\title{
AC 2010-1929: THE EFFECT OF PEER INSTRUCTION ON STUDENTS' CONSTRUCTION OF CONCEPTUAL UNDERSTANDING IN THERMODYNAMICS
}

\section{Bill Brooks, Oregon State University}

Bill Brooks is a PhD student in the School of Chemical, Biological and Environmental Engineering at Oregon State University. He is the primary programmer for the WISE learning tool. As an undergraduate student, he studied hardware engineering, software engineering, and chemical engineering. His thesis research involves investigating the interplay of content, pedagogy, and technology in student learning.

\section{Milo Koretsky, Oregon State University}

Milo Koretsky is an Associate Professor of Chemical Engineering at Oregon State University. He currently has research activity in areas related to thin film materials processing and engineering education. He is interested in integrating technology into effective educational practices and in promoting the use of higher level cognitive skills in engineering problem solving. Dr. Koretsky is a six-time Intel Faculty Fellow and has won awards for his work in engineering education at the university and national levels. 


\title{
The Effect of Peer Instruction on Students' Construction of Conceptual Understanding in Thermodynamics
}

\begin{abstract}
Many engineering classes emphasize student problem-solving skills almost to the exclusion of the understanding of underlying concepts. However, with this type of instruction, students are better rewarded by rote learning than by conceptual understanding. However, it has also been shown that the lack of conceptual understanding severely restricts the students' ability to solve a new problem since they do not have the functional understanding to use their knowledge in new situations. Alternatively, learning with understanding makes new learning easier, and leads to the development of expertise. Peer Instruction is a structured questioning process that actively involves all students in the class. In Peer Instruction, an instructor presents a multiple-choice conceptual question to the class. Students answer individually at first and next are shown a "poll" of the class responses. They then form groups and discuss the problem with peers, and finally answer again individually. Peer instruction encourages students to reflect on the problem and think through the arguments being developed and put them into their own words. Just as importantly, it provides both student and instructor with feedback regarding student understanding of the concept.
\end{abstract}

This study uses the Web-based Interactive Science and Engineering (WISE) Learning Tool as a platform to investigate the effectiveness of Peer Instruction on the explicit understanding of undergraduate students in chemical engineering thermodynamics. WISE is designed to utilize the college's Wireless Laptop Initiative so that every student in a class is simultaneously engaged. The cohort in this study was 64 students in the second term of a junior level chemical engineering thermodynamics class. No rationalizations were provided for answer choices; instead, each time students answered, they were asked to reflect on their choice and provide a short written explanation. They were also asked to indicate their confidence in the answer chosen. The student explanations, both before and after group discussion, were coded based on completeness and correctness. Four question pairs were analyzed, two in which a majority of the class initially reported the correct multiple choice answer and two in which the minority had the correct answer. On exercises in which the popular answer is also the correct answer, analysis of code gains compared to code losses indicate a statistically significant increase in apparent understanding. However, on those exercises in which the majority of the class chose incorrectly, there was no statistically significant improvement of understanding for the class as whole. Furthermore, in these cases there were a significant number of students that changed their answer to the popular, incorrect answer. These results lend support to the theory of social constructivism and the consensuality principle, and can help guide the use of Peer Instruction in the classroom.

\section{Introduction}

Many engineering classes use lecture based instructional delivery and emphasize routine problem-solving skills. This type of instruction can reward students more for rote learning than conceptual understanding. ${ }^{1}$ In fact, physics students showed a $70 \%$ success rate on a numerical problem whereas only a $10 \%$ success rate on a conceptual problem on the same concept. ${ }^{2}$ 
Similarly, a study of chemistry students demonstrated a $95 \%$ success rate on numerical problems as compared to a $38 \%$ rate on conceptual problems. ${ }^{3}$ However, it has been shown that the lack of conceptual understanding severely restricts the students' ability to solve new problems since they do not have the functional understanding to use their knowledge in new situations. ${ }^{4}$ Streveler et al. ${ }^{5}$ argue that the construction of conceptual knowledge is central to the development of expertise in engineering. Active, student centered learning environments are more effective than traditional lecture based methods at promoting conceptual understanding. ${ }^{6,7}$ In this study, we examine the ability of students to learn from their peers as part of one active learning technique, Peer Instruction.

Peer Instruction is a structured questioning process that actively involves all students in the class. ${ }^{8-10}$ In this technique, a multiple choice 'conceptest' or 'clicker question' is presented to the class. The class first answers the question individually. Depending on the aggregate response, students can be encouraged to discuss the answer in small groups and then individually submit a final answer. This sequence is then typically followed by a class wide discussion. In this way, the instructor can dynamically adjust the pace and extent of coverage to match student learning. Peer Instruction prompts students to actively engage in their own learning, to think critically about the material during class, and to learn and teach each other. This instructional technique is well established in the sciences. ${ }^{11-13}$ Over the past decade, it has be incorporated into the engineering instruction in Australia ${ }^{14}$ and Europe ${ }^{7,15}$, and is now being integrated into engineering instruction in the United States ${ }^{16}$ as well.

When Peer Instruction was originally introduced, the class response was tallied with flashcards and/or a show of hands, but now is usually done electronically, most commonly with personal response systems (clickers). In the study presented in this paper, the Web-based Interactive Science and Engineering (WISE) Learning Tool is used to collect student responses. ${ }^{17}$ WISE is designed to utilize the College of Engineering's Wireless Laptop Initiative and allows for a wide variety of question and response types. In addition to multiple choice answers, students provide short answer written explanations of why they selected an answer. This method prompts the students to be reflective; they are encouraged to think about their reasons for an answer. It also provides insight into their thought processes and how those processes change with Peer Instruction. In their responses, students also provide an indication of their confidence and identify the other members of the group with whom they worked.

A high quality conceptual question is necessary for Peer Instruction to be effective. Such questions are designed to be conceptually challenging and typically require no computation so that students cannot mechanically rely on equations to obtain the answer. They are designed to elicit or reveal pre-existing thinking, apply ideas in new contexts, ask students to qualitatively predict what will happen, or relate graphical and mathematical representations. ${ }^{10}$ High quality questions can be borrowed or modified from domain specific concept inventories (CIs). CIs are validated and reliable multiple choice instruments that explore students' conceptual understanding in a given subject area; they provide researchers with a common instrument that can be used to measure the improvement in student achievement after a unit of instruction. ${ }^{18}$ The most pertinent to this study are the CIs in thermodynamics. ${ }^{19-21}$ 
Peer Instruction has been shown to promote conceptual learning. For example, Smith et al. ${ }^{10}$ compare student responses to conceptual questions in genetics before and after group discussion. By examining student responses to the identical conceptual question and also an isomorphic question, a question on the same concept with different surface features, they show group discussion enhances understanding, even when none of the students in the group have the correct answer initially. Nicol and Boyle ${ }^{22}$ compare Peer Instruction with the technique of class-wide discussion. The authors argue that Peer Instruction is more effective. Since students first think about the question individually, they construct their own ideas and are better able to engage in dialogue and defend their answers or identify gaps in their thinking when interacting with their peers. As a consequence, these students are less likely to adopt the reasoning given by the more dominant students. Singh ${ }^{23}$ performed a controlled study and showed that students in pairs outperformed individuals in conceptual questions. In some cases, the pair was able to determine a correct answer even when both individuals were initially wrong. She attributes this outcome to co-construction of knowledge. Additionally, she found that the pair performance score was similar whether they first responded individually or not.

Research on self-explanation suggests that in formulating arguments and presenting them to others, students come to a deeper understanding of concepts. ${ }^{24}$ Thus, it has been argued that a key attribute of Peer Instruction is the facilitation of student-to-student and student-to-instructor interactions that allow students to negotiate meaning and construct understanding. ${ }^{25}$ However, researchers are only beginning to systematically measure and understand how teaching and learning unfold in this environment. Van Dijk et al. ${ }^{15}$ showed that Peer Instruction without the group discussion step produced significantly lower scores on a content post-test than with group discussion. And Turpen and Finkelstein ${ }^{26}$ reported the variation in instructor's techniques when implementing Peer Instruction (whether they walked around the class during discussion, whether they answered questions, and if there was an explicit individual response before group discussion). The study reported in this paper seeks to relate the reflective cognitions of students before and after group discussion to their multiple choice responses. Specifically, the research questions are:

- Does Peer Instruction help students that don't initially 'get it', to gain in understanding of difficult concepts in chemical thermodynamics?

- Do students that do initially 'get it' develop a more explicit understanding of difficult concepts in chemical thermodynamics after Peer Instruction?

- How does the display of the initial individual multiple choice response distributions to the class affect the content of the group discussion?

\section{Methods}

Sixty four students enrolled in the junior-level undergraduate Chemical Engineering Thermodynamics II course at a large public university participated in the study. The research was approved by the institutional review board and participants signed informed consent forms.

Conceptual exercises were assigned using WISE. Students were asked to choose a multiple choice answer, write a short answer explanation, and report their confidence. A distribution of the responses was displayed in bar graph form after the question was answered. In most cases, 
the class was encouraged to self-select groups of two or three students and discuss their answers. During this group discussion, the instructor did not interact with the groups directly except to answer general questions. Therefore, the responses were entirely comprised of the coconstruction within the student group. The exercise was assigned again and, in addition to the responses above, students identified the members of their Peer Instruction group. In all cases, a class wide discussion followed.

In this paper, a subset of four question pairs (eight exercises) are analyzed and labeled Throttling Valve $^{21}$, Spray Can, Mixing, and Equilibrium ${ }^{16}$. These exercises were delivered using the Peer Instruction method described above. A ninth exercise, labeled Adiabatic Air ${ }^{19}$, was also studied. Group discussion and follow-up were not used with this question. Screen shots of these five questions, as they were asked to the students, are shown in Appendix A. This subset of nine exercises had 557 responses; 517 had a definitive short-answer written explanation and 403 had a confidence value. Of the question pairs, 388 netted 194 code-able pairs of pre and post group

Table 1. Coding scheme for conceptual questions

\begin{tabular}{|c|c|c|c|c|c|c|}
\hline Code & Spray Can & Mrxing & Equilibrium & Adiabatic Air & \begin{tabular}{|l} 
Throttling \\
Valve
\end{tabular} & \\
\hline 1 & $\begin{array}{l}\text { Attractive forces } \\
\text { would hold the } \\
\text { molecules } \\
\text { together, } \\
\text { reducing the } \\
\text { pressure }\end{array}$ & $\begin{array}{l}\text { Since delta } h \text { is } \\
\text { positive, energy is } \\
\text { released, raising } \\
\text { the temperature }\end{array}$ & $\begin{array}{c}\text { Condenses } \\
\text { because of } \\
\text { constant volume }\end{array}$ & $\begin{array}{c}\text { Generally } \\
\text { imcorrect- } \\
\text { adiabatic } \\
\text { meansno } \\
\text { temperature } \\
\text { change }\end{array}$ & $\begin{array}{c}\text { Idealgas law - } \\
\text { implicit } \\
\text { constant } \\
\text { volume } \\
\text { assumption }\end{array}$ & \multirow[t]{2}{*}{ Incorrect } \\
\hline 2 & $\begin{array}{l}\text { Pressure } \\
\text { increases } \\
\text { because of the } \\
\text { attractive } \\
\text { molecular } \\
\text { interactions }\end{array}$ & $\begin{array}{l}\text { Some element is } \\
\text { missing, i.e. } \\
\text { positive delta } \mathrm{h} \\
\text { means } \\
\text { endothermic and } \\
\text { tempera ture goes } \\
\text { down }\end{array}$ & $\begin{array}{c}\text { Vaporizes } \\
\text { because of } \\
\text { Raoult's Law }\end{array}$ & $\begin{array}{c}\text { Ideal gas law } \\
-\mathrm{P} \text { is directly } \\
\text { proportional } \\
\text { to } \mathrm{T}\end{array}$ & $\begin{array}{c}\text { Idealgas law - } \\
\text { explicit } \\
\text { constant } \\
\text { volume } \\
\text { assumption }\end{array}$ & \\
\hline 3 & $\begin{array}{l}\text { Entha hy is less, } \\
\text { to a chieve } \\
\text { equilibrium, } \\
\text { entropy must be } \\
\text { less and pressure } \\
\text { greater }\end{array}$ & $\begin{array}{l}\text { The positive delta } \\
\text { hmeans energy is } \\
\text { needed for the } \\
\text { mixing and it } \\
\text { comes from } \\
\text { sensible heat }\end{array}$ & $\begin{array}{c}\text { Saturation } \\
\text { pressure and } \\
\text { liquid mole } \\
\text { fraction are } \\
\text { constant so water } \\
\text { must vaponize to } \\
\text { increase vapor } \\
\text { phasemole } \\
\text { fraction }\end{array}$ & $\begin{array}{c}\text { Implicit } \\
\text { energy } \\
\text { balance - } \\
\text { system does } \\
\text { work, losing } \\
\text { heat }\end{array}$ & $\begin{array}{l}\text { Misconceived } \\
\text { energy balance }\end{array}$ & $\begin{array}{l}\text { Explanation } \\
\text { Quality }\end{array}$ \\
\hline 4 & $\begin{array}{l}\text { Same as } 3 \text { and } \\
\text { explicitly states } \\
\text { that the increase } \\
\text { in pressure } \\
\text { comes from } \\
\text { decrease in } \\
\text { entropy }\end{array}$ & $\begin{array}{c}\text { Same as } 3 \text { and } \\
\text { mixing requires } \\
\text { energy because } \\
\text { the unlike } \\
\text { intermolecular } \\
\text { interactions have } \\
\text { less stability }\end{array}$ & $\begin{array}{l}\text { Same as } 3 \text { and } \\
\text { includes a } \\
\text { statement about } \\
\text { howno matter } \\
\text { howmuch the } \\
\text { vaporphase } \\
\text { mole fraction } \\
\text { can be increased, } \\
\text { it can't reach the } \\
\text { onginal } \\
\text { equilibrium } \\
\text { conditions }\end{array}$ & $\begin{array}{c}\text { Explicit } \\
\text { energy } \\
\text { balance - } \\
\text { some of the } \\
\text { energy in the } \\
\text { initial } \\
\text { tempera ture } \\
\text { will be } \\
\text { converted to } \\
\text { work to raise } \\
\text { the piston }\end{array}$ & $\begin{array}{c}\text { Proper energy } \\
\text { balance }\end{array}$ & $\begin{array}{l}\text { Correct and } \\
\text { Well Reasoned }\end{array}$ \\
\hline
\end{tabular}

interaction explanations. Finally, Adiabatic Air netted 61 code-able pre-PI explanations. The average response time on these nine exercises was $7 \mathrm{~min}$. with a standard deviation of 3 min. 
The mixed methodological basis of this research is grounded in a phenomenological perspective of ascertaining how student multiple choice and short answer explanations reflect conceptual understanding, and how that understanding changes as a result of group discussion. Coding the short answer follow-up responses involved using a technique similar to that of Newcomer and Steif $^{27}$ in their analysis of written explanations to a concept question in statics. The process involves proposing a code, coding individually, comparing amongst the coders, modifying the code, and repeating until convergence. A hierarchical coding scheme was created for each exercise which incorporates and ranks the important concepts and misconceptions. Table 1 describes the coding scheme that was used for each of the exercises. Codes ascend from 1 (incorrect) to 4 (correct and well reasoned) with a higher code indicating a more appropriate explanation.

Two researchers coded the written explanations for one of the exercises (Adiabatic Air). Values of inter-rater reliability using the Cohen's Kappa ( $\kappa)$ statistic is 0.80 , indicating reasonable agreement. Only one of the coded responses had a discrepancy greater than one code value. The statistical significance of change in multiple choice responses or coded quality of response is reported using a non-parametric sign test and the statistical significance of the correctness, consensuality and confidence relationship is reported using multi-factor analysis of variance.

\section{Results and Discussion}

\section{A Multiple choice responses}

Table 2 shows a summary of the distribution of multiple choice responses for the nine exercises, including the percentage correct and the percentage of students who chose each incorrect response. The exercises labeled "pre" are based on the initial individual student responses and those labeled "post" are individual responses after group discussion. On two exercises, Throttling Valve and Equilibrium, the majority of students initially chose the same incorrect answer while the majority chose the correct answer on Spray Can and Mixing. These sets are labeled, Consensually Wrong and Consensually Correct, respectively.

Table 2. Distribution of student responses to multiple-choice portions of the exercises

\begin{tabular}{|l|l|c|ccc|}
\hline \multicolumn{2}{|l|}{ Exercise } & Correct \% & Wrong A \% & Wrong B \% Wrong C \% \\
\hline \multirow{5}{*}{ Consensually Wrong } & Throttling Valve - pre & 13 & 61 & 25 & 1 \\
& Throttling Valve - post & 10 & 81 & 9 & 0 \\
\cline { 2 - 6 } & Equilibrium - pre & 10 & 48 & 38 & 5 \\
& Equilibrium - post & 7 & 60 & 33 & 0 \\
\hline \multirow{5}{*}{ Consensually Correct } & Spray Can - pre & 56 & 31 & 9 & 4 \\
& Spray Can - post & 76 & 24 & 0 & 0 \\
\cline { 2 - 6 } & Mixing - pre & 63 & 31 & 4 & 1 \\
& Mixing - post & 94 & 5 & 2 & 0 \\
\hline & Adiabatic Air & 89 & 7 & 3 & 1 \\
\hline
\end{tabular}




\section{B Short answer coding}

Table 3 shows a summary of the number of responses for each code category (Table 1) on the short written explanations. For each exercise, the coded written explanations are separated according to correct and incorrect multiple choice selections. In general, the correct multiple choice responses were associated with higher code values. The explanation coding scheme is expected to correlate with correctness of multiple choice responses, since students with richer conceptual explanations are more likely to get the problem correct. On the two consensually wrong exercises, Throttling Valve and Equilibrium, 9 of the 10 correct multiple choice responses were coded at the highest level (4) after group discussion.

Table 3. Distribution of short answer follow-up explanation codes, before and after group discussion

\begin{tabular}{|c|c|c|c|c|c|c|c|c|}
\hline \multirow[b]{2}{*}{ Code } & \multicolumn{4}{|c|}{ Pre discussion } & \multicolumn{4}{|c|}{ Post discussion } \\
\hline & 1 & 2 & 3 & 4 & 1 & 2 & 3 & 4 \\
\hline Throttling Valve - correct & 0 & 0 & 1 & 8 & 0 & 0 & 1 & 5 \\
\hline Throttling Valve -incorrect & 19 & 11 & 17 & 1 & 27 & 17 & 14 & 0 \\
\hline Equilibrium - correct & 1 & 3 & 0 & 1 & 0 & 0 & 0 & 4 \\
\hline Equilibrium - incorrect & 32 & 8 & 13 & 0 & 26 & 14 & 10 & 0 \\
\hline Spray Can - correct & 13 & 6 & 7 & 0 & 22 & 8 & 9 & 4 \\
\hline Spray Can - incorrect & 20 & 2 & 0 & 0 & 13 & 0 & 1 & 0 \\
\hline Mixing - correct & 9 & 17 & 14 & 1 & 6 & 27 & 20 & 3 \\
\hline Mixing - incorrect & 17 & 1 & 0 & 0 & 3 & 0 & 0 & 0 \\
\hline Adiabatic Air - correct & 2 & 20 & 5 & 26 & & & & \\
\hline Adiabatic Air - incorrect & 7 & 1 & 0 & 0 & & & & \\
\hline
\end{tabular}

\section{C Change in multiple choice response after group discussion}

The effect of group discussion on the students' selection of multiple choice answers is presented. For the four exercise pairs, the number of students who changed their answers from incorrect to correct (labeled "to correct") or from correct to incorrect (labeled "from correct") is presented in Figure 1A. Sign tests show statistical significance in the difference in number between "to correct" and "from correct" for the Spray Can ( $\mathrm{n}=20, \mathrm{x}=3, \mathrm{p}=0.002)$ and Mixing $(\mathrm{n}=25, \mathrm{x}=$ $3, \mathrm{p}=0.000$ ) exercises. On the other hand, the Consensually Wrong question pairs, Throttling Valve and Equilibrium were too few in number to show significance. However, in these cases, more students switched from the correct multiple choice answer to incorrect than incorrect to correct. Similarly, Figure 1B shows the changes to the consensual multiple choice answer (labeled "to consensual") and from the consensual answer (labeled "from consensual"). In all cases, more students changed "to consensual" than "from consensual". Sign tests show significance for changes to the consensual answer for one consensually wrong answerThrottling Valve $(\mathrm{n}=21, \mathrm{x}=3, \mathrm{p}=0.001)$ and the consensually correct exercises - Spray Can ( $=20, \mathrm{x}=3, \mathrm{p}=0.002)$ and Mixing $(\mathrm{n}=25, \mathrm{x}=3, \mathrm{p}=0.000)$. While the changes to Equilibrium were not statistically significant to $95 \%$ confidence $(n=14, x=4, p=0.11)$, over twice the number of students switched "to consensual" than "from consensual", even though the "to consensual" answer was incorrect. Essentially, more students tend to change to the consensual answer after group discussion, regardless of whether that answer is correct or not. 
A) Correct Answer

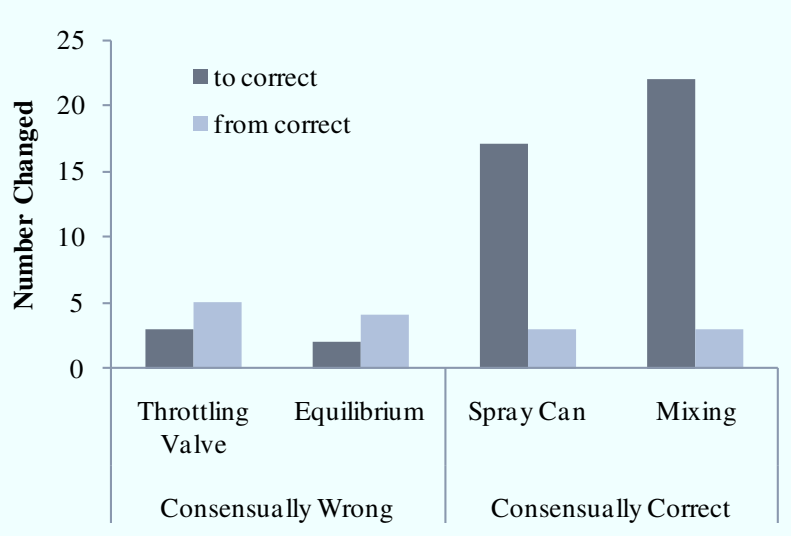

B) Consensual Answer

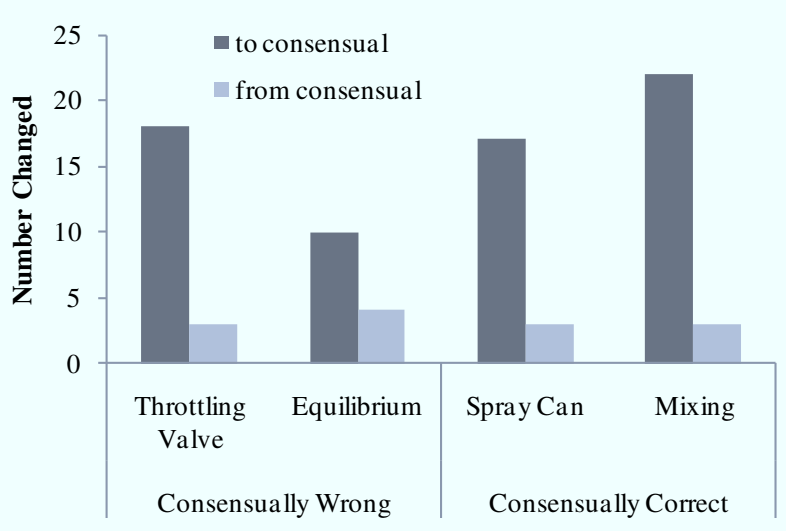

Figure 1. Changes to and from correct (A) and to and from consensual (B)

\section{D Change in codes of written explanations after group discussion}

Figure 2 shows the number of written explanations that improved (+ $\operatorname{code} \Delta$ ) or declined (- code $\Delta$ ) in code value after group discussion. Figure $2 \mathrm{~A}$ is organized by exercise. Again the sign test was used to determine significance. While all exercises resulted in a greater number of gains than losses, the Consensually Correct question pairs showed statistically significant gains, Spray Can $(\mathrm{x}=2, \mathrm{n}=25, \mathrm{p}=0.000)$ or nearly statistically significant gains, Mixing $(\mathrm{x}=9, \mathrm{n}=28$, $\mathrm{p}=0.059)$.

Figure 2B aggregates the coded written explanations of all question pairs and organizes them by the correctness of the multiple choice answers, before and after group discussion. Therefore, the categories become the number of code differences of students who: selected the correct multiple choice answer both before and after group discussion (labeled "correct to correct"), selected the correct multiple choice answer before then incorrect after (labeled "correct to incorrect"), selected the wrong answer before and correct after (labeled "incorrect to correct"), and had incorrect answer choices both before and after (labeled "incorrect to incorrect"). Significance can be shown for the differences in code changes $(+\operatorname{code} \Delta-$-code $\Delta)$ in three of the four categories. Correct to correct $(\mathrm{x}=7, \mathrm{n}=27, \mathrm{p}=0.012)$ and incorrect to correct $(\mathrm{x}=0, \mathrm{n}=22, \mathrm{p}=0.000)$ had more gains in code ratings $(+\operatorname{code} \Delta)$. Correct to incorrect $(\mathrm{x}=0, \mathrm{n}=9, \mathrm{p}=0.003)$ had a significant decline (- code $\Delta$ ). A statistically significant number of students who originally had the correct multiple choice answer improved their explanations after group discussion, and, therefore demonstrated more explicit understanding of difficult concepts in chemical thermodynamics. This result suggests that Peer Instruction, in the manner studied here, can help students develop richer explanations, even though they originally selected the correct multiplechoice answer. 

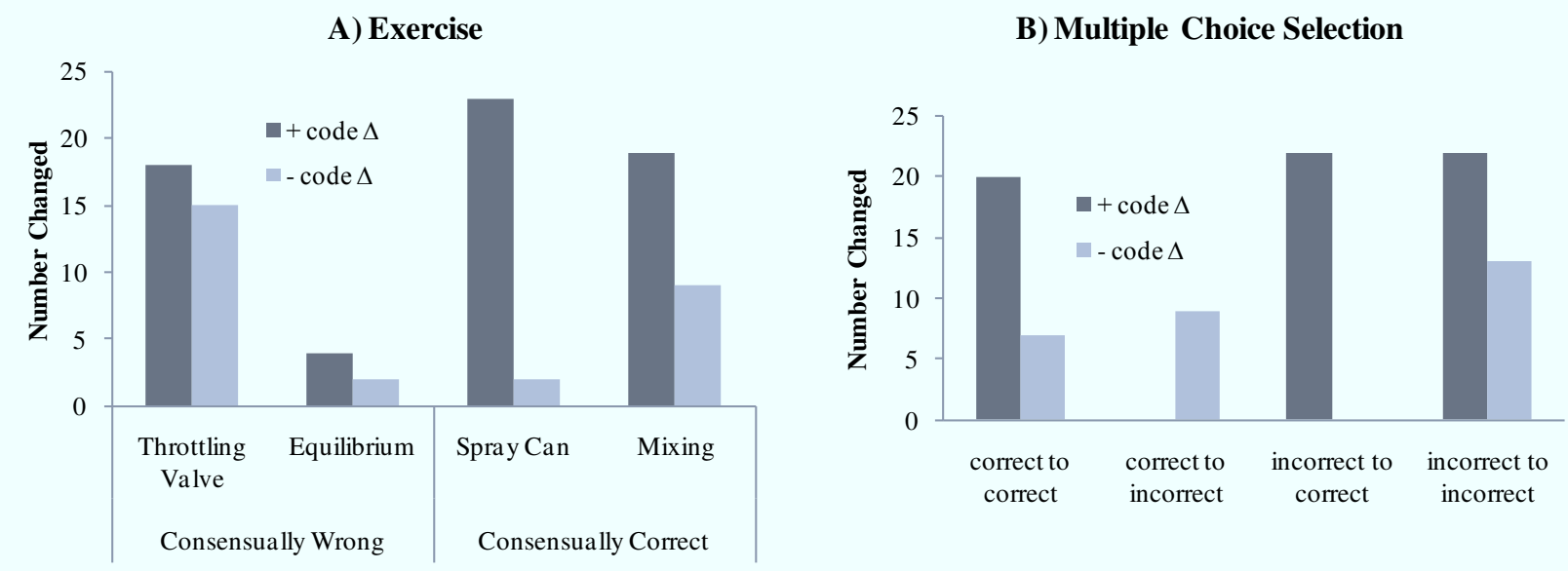

Figure 2. Explanation of code change (A) by exercise and (B) by multiple choice answer selection.

The number of explanations that improved or declined can also be viewed by multiple choice answer selection and consensuality. Figure 3 shows all of the significant explanation gains, shown above in the students that maintain a correct answer $(\mathrm{x}=7, \mathrm{n}=27, \mathrm{p}=0.012)$ and those that switch to the correct answer $(\mathrm{x}=0, \mathrm{n}=18, \mathrm{p}=0.000)$, are in the consensually correct question pairs (Figure 3A). The explanations that significantly declined (correct to incorrect, $\mathrm{x}=$ $0, \mathrm{n}=7, \mathrm{p}=0.008$ ) are in the consensually wrong question pairs (Figure $3 \mathrm{~B}$ ). When the answer is consensually wrong, the gains realized by Peer Instruction may be limited.

A) Consensually Correct

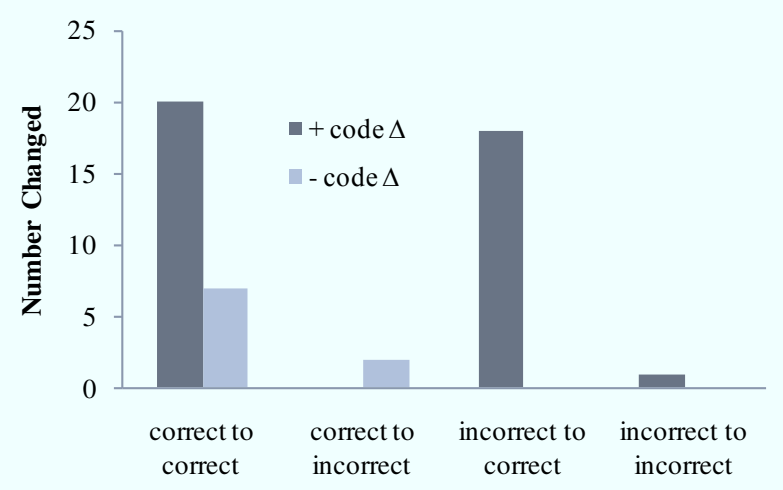

B) Consensually Wrong

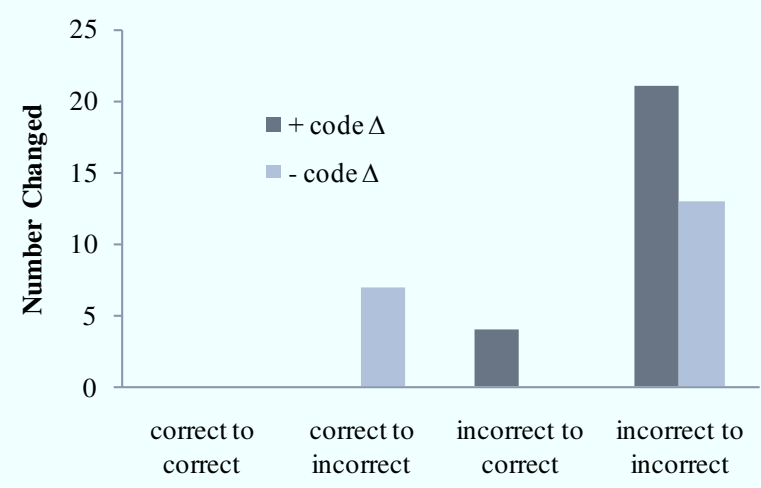

Figure 3. Explanation code improvement and decline organized by multiple choice answer selection for the consensually correct exercises (A) and the consensually wrong ones (B)

\section{E Student confidence before and after group discussion}

Figure 4 shows the average reported confidence for incorrect and correct multiple choice answers, grouped by exercise category of consensually correct (CC) and consensually wrong (CW). Figure 4A shows results before group discussion. There is no significant correlation between confidence and correctness or consensuality. Figure 4B shows results after group 
discussion. In this case, there is a correlation between confidence and consensuality, as determined by multi-factor ANOVA $(\mathrm{F}(1,169)=16.49$, MSE $=12.36, \mathrm{p}=0.000)$. Those students who chose the consensual answer were more confident, whether it was correct or not. In fact, those that had the correct non-consensual answer were the least confident of all cases in Figure 4.

A)

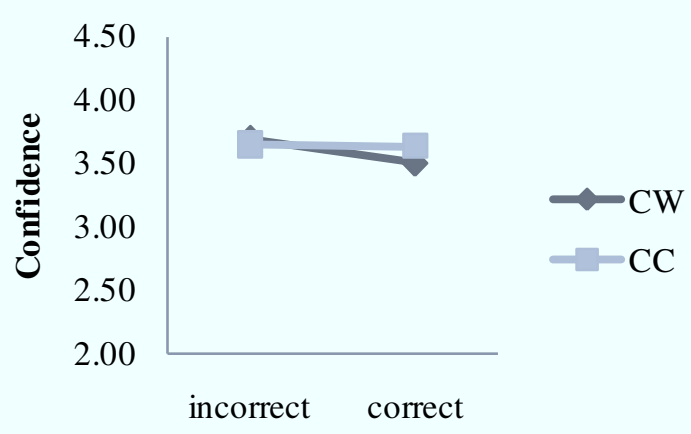

B)

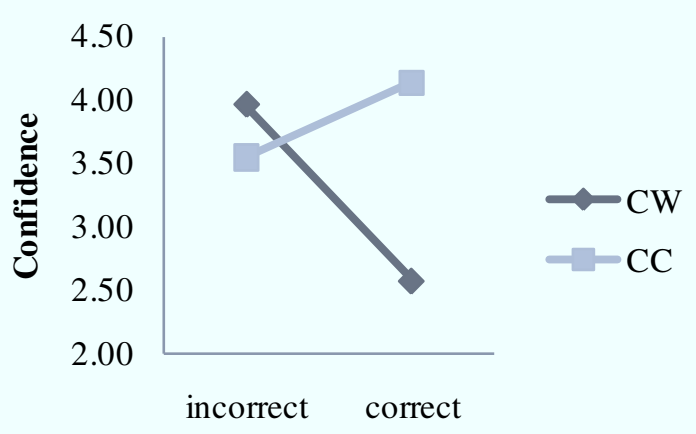

Figure 4. Confidence, Correctness, and Consensuality Pre (A) and Post (B) discussion (CC = Consensually Correct and $\mathrm{CW}=$ Consensually Wrong)

The consensuality principle proposed by Koriat ${ }^{28}$ states that metacognitive judgments are influenced by factors that make it compelling to the majority and can be independent of correctness. In our study, primary factors could be common misconceptions, the display of the initial multiple choice responses, and local majorities within a discussion group. In fact, Koriat states that for the case of incorrect responses, "metacognitive judgments will be counterdiagnostic of the correctness of the answer." While the study cited above was directed at a different domain (foreign language), the results presented in this paper suggest that the consensuality principle applies to conceptual questions in thermodynamics as well. It is reasonable to conclude that consensuality is an important factor to consider in the use of Peer Instruction in undergraduate chemical engineering thermodynamics.

The tendency for students to select the most popular answer after interaction could have several simultaneous root causes. It is possible that groupthink and the socio-cultural construct of how important it is for group members to fit in with their peers is a factor in the choice of the popular explanation and/or answer. That may be why Peer Instruction proved more beneficial than class wide discussion in the study by Nicol and Boyle ${ }^{22}$ discussed earlier. In the instructional design in these active learning pedagogies, the existence of groupthink shouldn't detract from the individual metacognitive judgments and the effects those initial judgments have on the direction of social learning. Moreover, the cases when the majority is initially wrong present a rich instructional opportunity. Hattie and Temperly ${ }^{29}$ argue that the most desirable circumstance for students to be receptive to feedback is when they have high confidence but are incorrect.

Given the negative impact on the confidence of the students that maintain a correct answer in spite of a consensually wrong answer, it might be useful to omit showing answer distributions between the individual work and group discussion. A controlled study of student multiple choice 
and written responses with and without intermediate display of the class results could help clarify this question.

\section{F Examples of student written explanations within a group}

It is instructive to examine the individual written responses both before and after group discussion. Such responses can provide evidence of the extent that individual responses change as a result of group discussion and the possible effect of the ideas of the other members of the group on each individual's response.

Consider, for example, the Throttling Valve, a consensually wrong question pair (See Appendix A, Figure A.1). The correct answer is " $\mathrm{T}_{2}=\mathrm{T}_{1}$ ". To solve this problem, students needed to understand two concepts. The correct logic could be written as follows: first, the steady-state energy balance across the valve shows that the enthalpy of the exit state, 2, equals the enthalpy of the inlet state, 1, i.e., it is an isenthalpic process; second, the enthalpy change of an ideal gas depends on temperature only. Therefore, since the enthalpy does not change, neither does the temperature. However, students commonly fail to consider an energy balance, and instead rely on faulty reasoning with multi-variable relationships using the ideal gas law, from which they conclude " $\mathrm{T}_{2}<\mathrm{T}_{1}$ ". This persistent misconception has been reported in physics classes. ${ }^{30}$

Tables 4 and 5 show the written responses of two representative groups, Group 1 and Group 2, respectively. The initial multiple choice responses for the students in Group 1 are all different. Student B, considers the energy balance and essentially has the correct explanation (flow work is not zero, but the flow work of the inlet and the outlet are the same). This view apparently influenced Student A whose response after group discussion demonstrates a significant improvement in reasoning, and even appears better than Student B's final explanation. While Student C maintains his/her original multiple choice answer, the written explanation is also improved. This example shows an effective influence of group discussion. 
Table 4. Group 1 explanations for the Throttling Valve exercise

\begin{tabular}{|c|l|l|}
\hline Student & Pre-Discussion Explanation & Post-Discussion Explanation \\
\hline \multirow{4}{*}{ A } & $\begin{array}{l}\text { PV/T = PV/T Due to pressure drop, the energy } \\
\text { must be going some where so temperature will } \\
\text { probably increase }\end{array}$ & $\begin{array}{l}\text { Since no work if (sic) being done and the system } \\
\text { is adiabatic we see no change in internal energy. } \\
\text { No change in internal energy for an ideal gas } \\
\text { means that temperature has not changed, no } \\
\text { change in temperature means the volumetric } \\
\text { flow rate must be changing. T1 must be equal to } \\
\text { T2. }\end{array}$ \\
\hline \multirow{5}{*}{ B } & $\begin{array}{l}\text { NO WORK IS DONE, AS THE PRESSURE } \\
\text { DECREASES THE VOLUMETRIC FLOW } \\
\text { RATE WILL INCREASE } \\
\text { PROPORTIONALLY. U REMAINS THE } \\
\text { SAME THEREFORE T REMAINS THE } \\
\text { SAME. ALSO THIS IS AN IDEAL GAS AND } \\
\text { THEREFORE WE HAVE NO FLOW WORK. }\end{array}$ & $\begin{array}{l}\text { I STILL CAN'T SEE ANY OTHER WAY OF } \\
\text { DOING THIS ONE, AND MY GROUP } \\
\text { MEMBERS WOULDN'T FIGHT ME ON IT, } \\
\text { SO I GOT TO SAY THAT THEY ARE EQUAL } \\
\text { BECAUSE THERE IS NO WORK BEING } \\
\text { DONE!!!! U=Q+W Q=0 }\end{array}$ \\
\hline \multirow{5}{*}{ C } & $\begin{array}{l}\text { There is less internal energy if the pressure } \\
\text { decreases }\end{array}$ & $\begin{array}{l}\text { Flow work is done the same amount of particles } \\
\text { esscap (sic) as are inputed (sic) rlaying (sic) that } \\
\text { there is an increase in velocity which is removed } \\
\text { from the temperature of T1 and thus to T2 is less } \\
\text { than that of T1 }\end{array}$ \\
\hline \multicolumn{2}{|c}{}
\end{tabular}

Table 5 shows similar data for Group 2. However, the impact of group discussion appears to be opposite. For example, while Student D initially considers energy in the written explanation, this student reverts to the common ideal gas misconception after group discussion, apparently influenced by both the views of Students $\mathrm{E}$ and $\mathrm{F}$ and the intermediate bar graph which showed the popularity of the consensually wrong answer.

Table 5. Group 2 explanations for the Throttling Valve exercise

\begin{tabular}{|c|l|l|}
\hline Student & \multicolumn{1}{|c|}{ Pre-Discussion Explanation } & \multicolumn{1}{|c|}{ Post-Discussion Explanation } \\
\hline D & $\begin{array}{l}\text { since well insulated and no work is being done, } \\
\text { delta U has to equal zero. This means that the } \\
\text { energy lost from the drop in pressure would lead to } \\
\text { an increase in temperature. }\end{array}$ & $\begin{array}{l}\text { Pv=RT .. therefore if pressure decreases while } \\
\text { volume remains the same then temperature must } \\
\text { decrease as well. }\end{array}$ \\
\hline \multirow{5}{*}{ E } & $\begin{array}{l}\text { The ideal gas equation explains the relationship } \\
\text { between pressure and temperature. There is no } \\
\text { change in molar amount or volume between the } \\
\text { two states. Only thing changing is pressure, and } \\
\text { from that temperature changes in the following } \\
\text { way; If pressure goes down, temperature must go } \\
\text { down as well for the equation to remain equal, } \\
\text { PV=nRT. }\end{array}$ & $\begin{array}{l}\text { The ideal gas law shows that temperature changes } \\
\text { directly proportional to pressure. If pressure goes } \\
\text { down, temperature goes down. Based on this } \\
\text { observation it can be shown that T2<T1. }\end{array}$ \\
\hline F & $\begin{array}{l}\text { Using Ideal gas law, if pressure decreases, then the } \\
\text { temperature must also decrease. }\end{array}$ & $\begin{array}{l}\text { Do (sic) to ideal gas law. If the pressure goes down, } \\
\text { then the temperature must go down. }\end{array}$ \\
\hline
\end{tabular}

The written responses for the Adiabatic Air exercise can be considered in this context (See Appendix A, Figure A.5). Again the response of temperature must be determined. The correct multiple choice answer is that the temperature decreases, and the correct written explanation is that the internal energy of the system decreases as the gas is used to do work on the 
surroundings, and since the internal energy of the ideal gas decreases, the temperature decreases. $89 \%$ of the students selected the correct multiple choice response. From this result, it would appear that the majority of the students had a conceptual understanding of the first law of thermodynamics for closed systems. However, in coding the short answer follow-ups, it was determined that 30 students applied the faulty ideal gas reasoning described above, even though the problem statement does not indicate the air is an ideal gas. In this case, misapplication of the ideal gas law can inadvertently lead to the correct multiple choice response. To some extent the Adiabatic Air and Throttling Valve exercises represent isomorphic problems; they both need students to apply an energy balance to predict the resulting temperature, and they both can elicit the ideal gas misconception. However, one applies to a closed system and the other to an open system.

\section{Summary}

This paper presents the use of the Web-based Interactive Science and Engineering (WISE) Learning Tool as a platform to investigate the effectiveness of Peer Instruction on the explicit understanding of undergraduate students in chemical engineering thermodynamics. The cohort was 64 students in the second term of a junior level chemical engineering thermodynamics class. No rationalizations were provided for multiple choice answers; instead, each time students answered, they were asked to reflect on their choice and provide a short written explanation. They were also asked to indicate their confidence in the answer chosen. The student explanations, both before and after group discussion, were coded based on completeness and correctness. Four question pairs were analyzed, two in which a majority of the class initially reported the correct multiple choice answer and two in which the minority had the correct answer. On exercises in which the popular answer is also the correct answer, analysis of code gains compared to code losses indicate a statistically significant increase in apparent understanding. However, on those exercises in which the majority of the class chose incorrectly, there was no statistically significant improvement of understanding for the class as whole. Furthermore, in these cases there were a significant number of students that changed their answer to the popular, incorrect answer.

There is often a conflict between experience based and information based metacognitive judgments. Experts have experience which helps them choose the proper information judgment. Concept-based reasoning and reflective explanation are intended to promote information based metacognition and higher level cognition. However the results of this study suggest that social cues can influence greatly the direction of learning in this type of group based active learning environment.

\section{References}

[1] Elby, A. (1999). Another reason that physics students learn by rote. American Journal of Physics, 67, S52. 
[2] McDermott, L. C. (2001). Oersted Medal Lecture 2001:"Physics Education Research-The Key to Student Learning”. American Journal of Physics, 69, 1127.

[3] Haláková, Z., \& Proska, M. (2007). Two Kinds of Conceptual Problems in Chemistry Teaching. Journal of Chemical Education, 84(1), 3.

[4] Bransford, J. D., Brown, A. L., Cocking, R. R., \& others. (2000). How people learn. National Academy Press Washington, DC.

[5] Streveler, R. A., Litzinger, T. A., Miller, R. L., \& Steif, P. S. (2008). Learning conceptual knowledge in the engineering sciences: Overview and future research directions. Journal of Engineering Education, 97(3), 279-294.

[6] Hake, R. R. (1998). Interactive-engagement versus traditional methods: A six-thousand-student survey of mechanics test data for introductory physics courses. American Journal of Physics, 66, 64-74.

[7] Poulis, J., Massen, C., Robens, E., \& Gilbert, M. (1998). Physics lecturing with audience paced feedback. American Journal of Physics, 66(5), 439-441.

[8] Mazur, E. (1997). Peer instruction. Prentice Hall Upper Saddle River, NJ.

[9] Mazur, E. (2009). EDUCATION: Farewell, Lecture? Science, 323(5910), 50.

[10] Smith, M. K., Wood, W. B., Adams, W. K., Wieman, C., Knight, J. K., Guild, N., et al. (2009). Why peer discussion improves student performance on in-class concept questions. Science, 323(5910), 122.

[11] Crouch, C. H., \& Mazur, E. (2001). Peer instruction: Ten years of experience and results. American Journal of Physics, 69, 970.

[12] Duncan, D. (2005). Clickers in the classroom. Addison Wesley, San Francisco.

[13] MacArthur, J. R., \& Jones, L. L. (2008). A review of literature reports of clickers applicable to college chemistry classrooms. Chemistry Education Research and Practice, 9(3), 187-195.

[14] Murray, M. H. (1999). Building networks through peer interaction. Journal of Professional Issues in Engineering Education and Practice, 125(4), 159-162.

[15] Van Dijk, L. A., Van Der Berg, G. C., \& Van Keulen, H. (2001). Interactive lectures in engineering education. European Journal of Engineering Education, 26(1), 15-28.

[16] Falconer, J. L. (2007). Conceptests for a Thermodynamics Course. Chemical Engineering Education, 41(2), 107.

[17] Koretsky, M., \& Brooks, B. (2008). A Web-based Interactive Science and Engineering Learning Tool that Promotes Concept-Based Instruction. In Proceedings of the Annual Conference of the American Society for Engineering Education.

[18] Hestenes, D., Wells, M., \& Swackhamer, G. (1992). Force Concept Inventory. The Physics Teacher, 30(3), 141-158.

[19] Midkiff, C., Litzinger, T., \& Evans, D. (2001). Development of Engineering Thermodynamics Concept Inventory instruments. In Frontiers in Education Conference, 2001. 31st Annual (Vol. 2, pp. F2A-F23 vol.2). doi: 10.1109/FIE.2001.963691. 
[20] Miller, R. L., Streveler, R. A., Olds, B. M., Nelson, M. A., \& Geist, M. R. (2005). Concept Inventories Meet Cognitive Psychology: Using Beta Testing as a Mechanism for Identifying Engineering Student Misconceptions. In Proceedings of the Annual Conference of the American Society for Engineering Education.

[21] http://www.mines.edu/research/cee/Misconceptions.html accessed Jan. 10, 2008.

[22] Nicol, D. J., \& Boyle, J. T. (2003). Peer Instruction versus Class-wide Discussion in Large Classes: a comparison of two interaction methods in the wired classroom. Studies in Higher Education, 28(4), 457-473.

[23] Singh, C. (2005). Impact of peer interaction on conceptual test performance. American Journal of Physics, 73, 446.

[24] Chi, M. T. (1996). Constructing self-explanations and scaffolded explanations in tutoring. Applied Cognitive Psychology, 10(7), 33-49.

[25] Judson, E., \& Sawada, D. (2002). Learning from past and present: Electronic response systems in college lecture halls. Journal of Computers in Mathematics and Science Teaching, 21(2), 167-182.

[26] Turpen, C., \& Finkelstein, N. D. (2009). Not all interactive engagement is the same: Variations in physics professors' implementation of Peer Instruction. Physical Review Special Topics-Physics Education Research, 5(2), 20101.

[27] Newcomer, J. L., \& Steif, P. S. (2008). Student Thinking about Static Equilibrium: Insights from Written Explanations to a Concept Question. Journal of Engineering Education, 97(4), 481-490.

[28] Koriat, A. (2008). Subjective Confidence in One's Answers: The Consensuality Principle. Journal of Experimental Psychology: Learning, Memory, and Cognition, 34(4), 945-959.

[29] Hattie, J., \& Timperley, H. (2007). The power of feedback. Review of Educational Research, 77(1), 81.

[30] Loverude, M. E., Kautz, C. H., \& Heron, P. R. (2002). Student understanding of the first law of thermodynamics: Relating work to the adiabatic compression of an ideal gas. American Journal of Physics 70, (2), 137-148. 


\section{Appendix A. Conceptual questions used in this study}

In this appendix, the five concept exercises, as presented to the students using the WISE interface are presented. Figure A.1 shows Throttling Valve, Figure A.2 shows Equilibrium, Figure A.3 shows Spray Can, Figure A.4 shows Mixing, and finally, Figure A.5 shows Adiabatic Air.

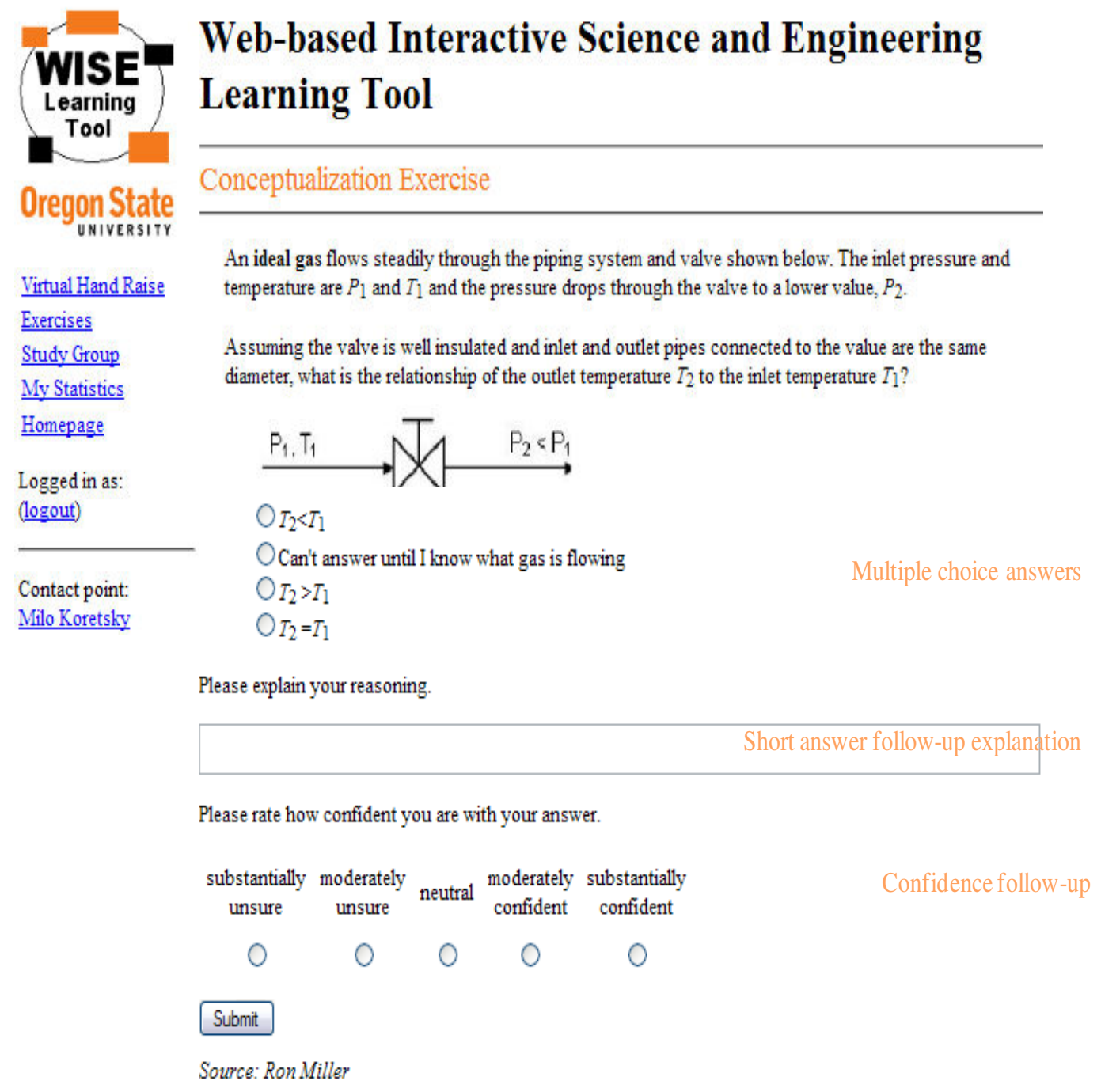

Figure A.1. Throttling Valve exercise 


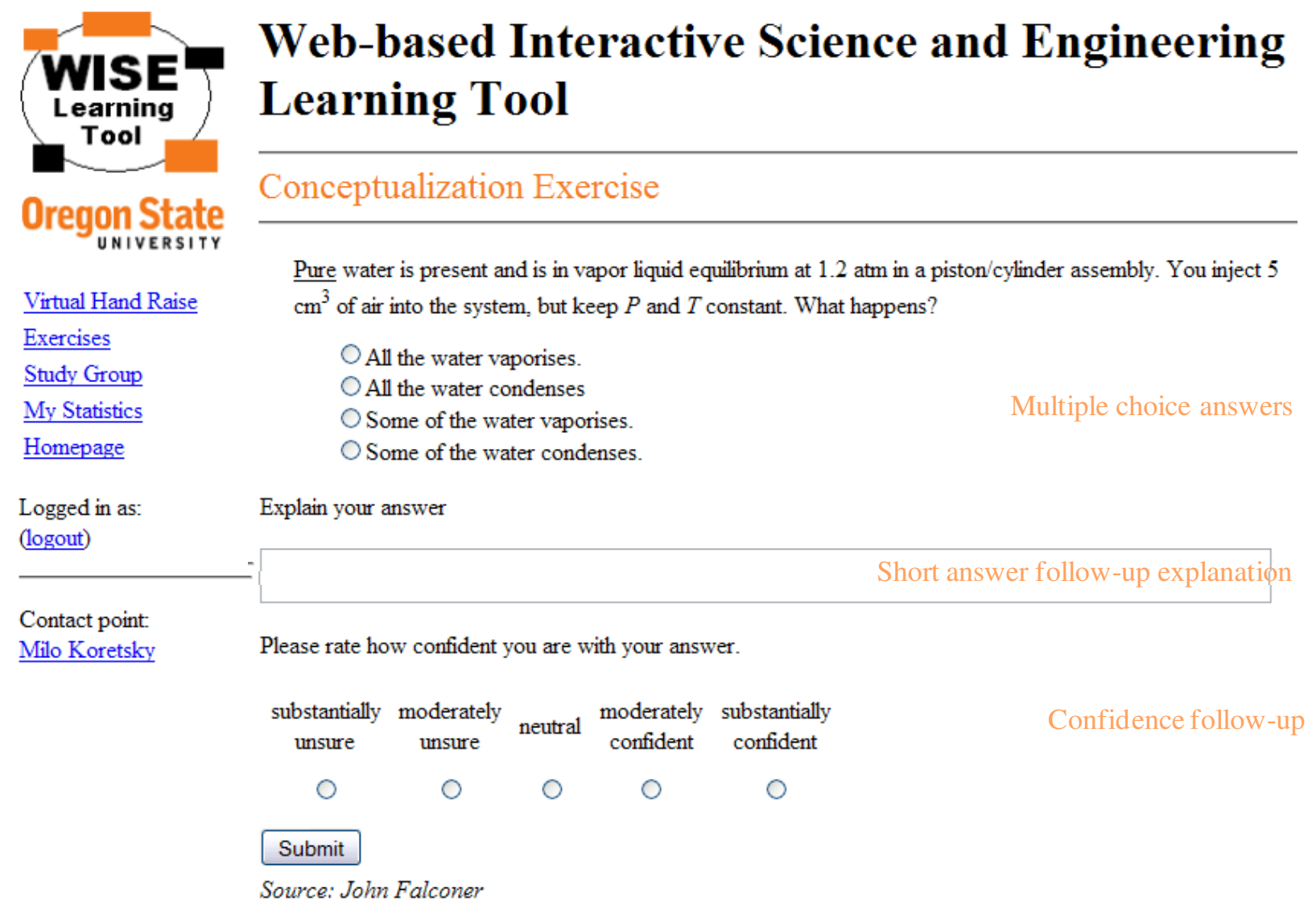

Figure A.2. Equilibrium exercise 


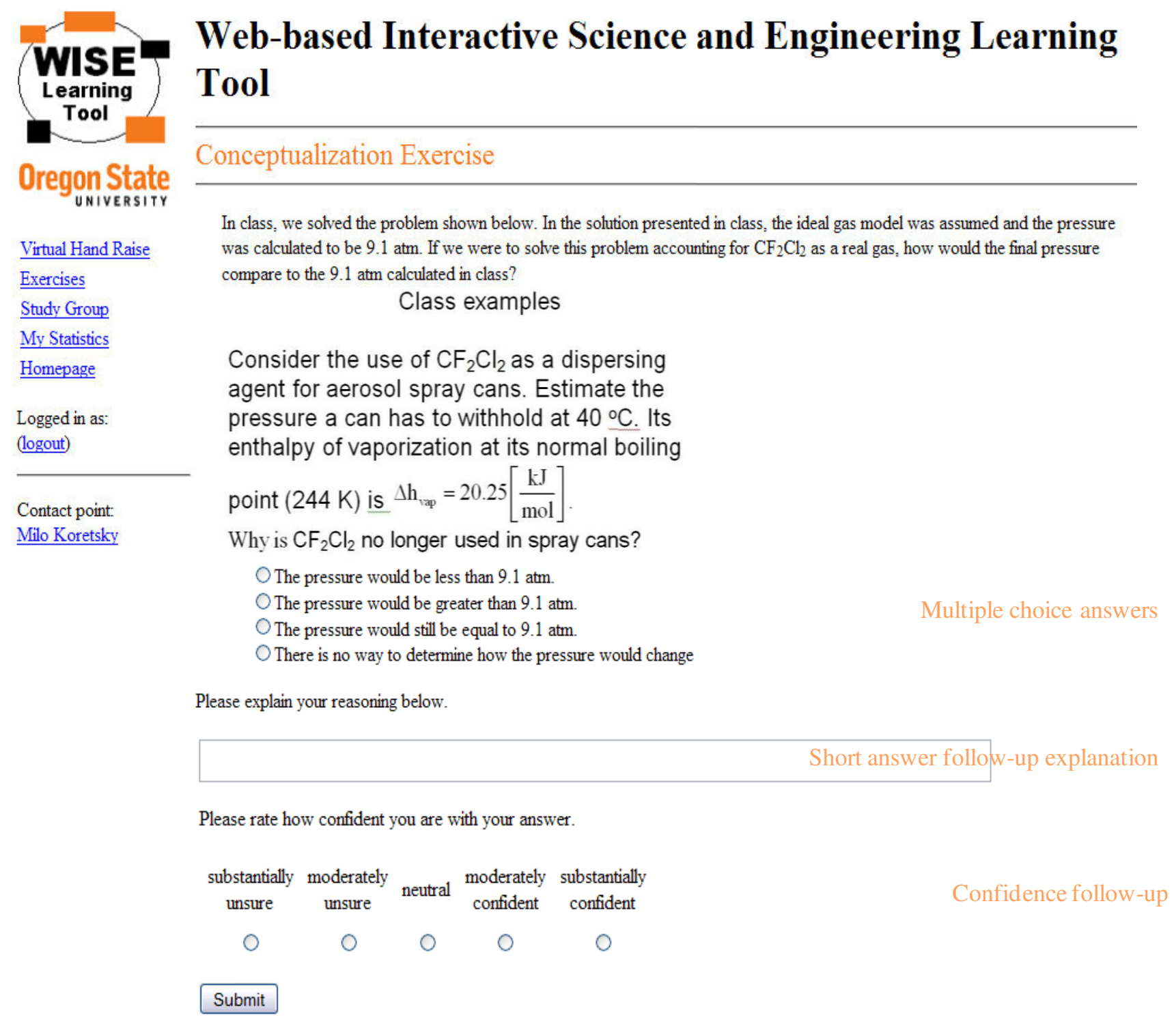

Figure A.3. Spray Can exercise 


\section{Web-based Interactive Science and Engineering Learning Tool}

\section{Conceptualization Exercise}

Oregon $\operatorname{State}$

Virtual Hand Raise

Exercises

Study Group

My Statistics

Homepage

Logged in as: (logout)

Contact point:

Milo Koretsky

The enthalpy of mixing for a mixture of cyclohexane and toluene is shown below. Consider the adiabatic mixing of

1 mole of cyclohexane and 1 mole of toluene at $25^{\circ} \mathrm{C}$. The final temperature will be:

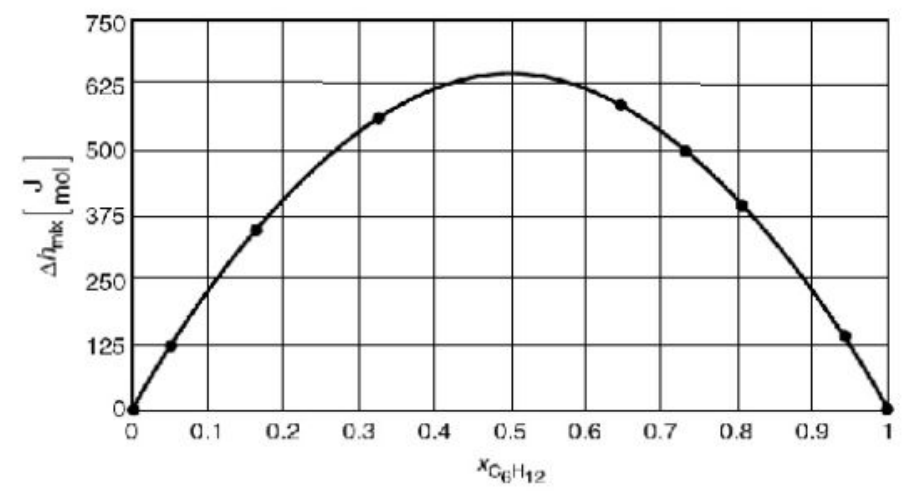

Less than $25^{\circ} \mathrm{C}$

Greater than $25^{\circ} \mathrm{C}$

Equal to $25^{\circ} \mathrm{C}$

Need more information

Explain your answer.

Please rate how confident you are with your answer.

$\begin{array}{ccccc}\begin{array}{c}\text { substantially } \\ \text { unsure }\end{array} & \begin{array}{c}\text { moderately } \\ \text { unsure }\end{array} & \text { neutral } & \begin{array}{c}\text { moderately } \\ \text { confident }\end{array} & \begin{array}{c}\text { substantially } \\ \text { confident }\end{array} \\ 0 & 0 & 0 & 0 & 0\end{array}$

Figure A.4. Mixing exercise 


\section{WISE Web-based Interactive Science and Engineering Learning Learning Tool}

\section{Oregon State}

Virtual Hand Raise

Exercises

Study Group

My Statistics

Homepage

Logged in as:

(logout)

Contact point:

Milo Koretsky

\section{Conceptualization Exercise}

Air at high pressure and ambient temperature is contained in a perfectly insulated piston-cylinder assembly as shown. Stops prevent the piston from moving up. The stops are then removed and the piston quickly rises into the atmospheric pressure air above it until a second set of stops is encountered that prevents it from leaving the cylinder.

The temperature of the air in the cylinder:
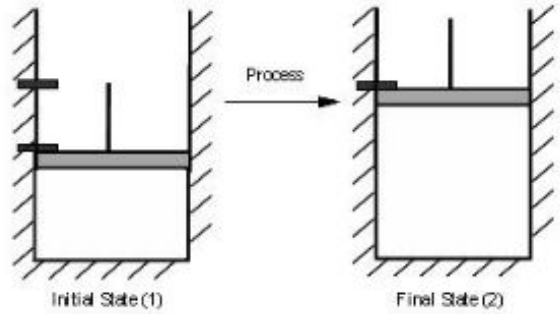

Decreases

Oncreases

ORemains the same

Onsufficient information

Explain Your answer

Written explanation

Please rate how confident you are with your answer.

substantially moderately neutral moderately substantially

unsure unsure neutral confident confident

$0 \quad 0 \quad 0 \quad 0$

Confidence follow-up

\section{Submit}

Source: Midkiff, Clark

Figure A.5. Adiabatic Air exercise 